\title{
INVESTIMENTO EMPRESARIAL E REFLEXOS NA GESTÃO DO CAPITAL DE GIRO
}

\author{
M. M. REIS ${ }^{1^{*}}$, D. F. L. SANTOS ${ }^{* 2}$ \\ Universidade Estadual Paulista \\ david.lopes@fcav.unesp.br*
}

Submetido 15/01/2016 - Aceito 18/09/2017

DOI: $10.15628 /$ holos.2017.3997

\section{RESUMO}

Este trabalho busca compreender como as variações nos investimentos de longo prazo influenciam a gestão do capital de giro das empresas brasileiras. A amostra computou 255 empresas não financeiras de capital aberto da BM\&FBOVESPA, com dados financeiros para o período de 2011 a 2015. A partir de uma abordagem quantitativa com base na análise de regressão com dados em painel, refutou-se a expectativa de trade-off entre liquidez e rentabilidade tendo em vista que os investimentos em ativos imobilizados impactam positivamente o Saldo de Tesouraria e influenciam no crescimento da Necessidade de Capital de Giro, o que denota preocupação por parte das empresas em manter a liquidez. Constatou-se, ainda, que o efeito positivo dos investimentos em Imobilizado no Saldo de Tesouraria e Necessidade de Capital de Giro reforçam que as fontes de financiamento de Longo Prazo devem ser suficientes para garantir os investimentos de longo prazo e a folga financeira.

PALAVRAS-CHAVE: Capital de Giro, Finanças de Curto Prazo, Investimento, Modelo Dinâmico

\section{BUSINESS INVESTMENT AND REFLECTIONS ON WORKING CAPITAL MANAGEMENT}

\begin{abstract}
This work aims to understand how variations in longterm investments influence on working capital management Brazilian firms. The sample computed 255 non-financial companies with stock traded in the BM\&FBOVESPA and financial data to period between 2011 to 2015. From quantitative methods by regression analysis using panel data, refuted the expectation of trade-off between liquidity and profitability, given that
\end{abstract}

the investments in fixed assets positively impact the Treasury and influence the growth of Need Working Capital, which shows concern for companies to maintain liquidity. It was also found that the positive effect of investments in Fixed Assets in the Treasury and Need Working Capital reinforce the Long-term funding sources should be sufficient to ensure the Fixed Assets and the financial slack.

KEYWORDS: Working Capital, Finance Short-term, Investment. Dynamic Model 


\section{INTRODUÇÃO}

A gestão do capital de giro é um dos temas centrais nas Finanças Corporativas (Berk, Demarzo \& Harford, 2010), (Assaf, 2005). No entanto há uma proeminência nos estudos da área financeira nos temas associados às decisões de longo prazo quanto a investimentos, estrutura de capital e risco (Almeida \& Eid., 2014).

As evidências de assimetria de informação nos mercados financeiros e a presença de custos associados à agência têm alçado maior importância à gestão do capital de giro das empresas (Baños-Caballero, García-Teruel \& Martinez-Solano, 2014). Em adição, o estágio atual de competitividade entre as empresas exige, igualmente, robustez no controle dos custos associados ao negócio e maior nível de serviço aos clientes, sendo que as duas pontas exercem influência na gestão do capital de giro (Lind, Pirtillä, Viskari, Schupp \& Karri, 2012).

A decisão entre investir em ativos não circulantes ou manter a liquidez constitui uma das principais decisões empresariais, pois gera reflexos na rentabilidade futura e/ou a solvência no curto e médio prazo (Matias, 2007) (Palombini \& Nakamura, 2012).

Portanto, a necessidade de realizar investimentos empresariais implica no acréscimo no volume de atividades da empresa que impacta o capital de giro e a estrutura de financiamento que garanta a liquidez (Knauer \& Wöhrmann, 2013).

No Brasil as questões que envolvem a gestão do capital de giro são ainda mais relevantes em função das limitações existentes do mercado de crédito (Nascimento, Espejo, Voese, Pfitscher \& Teles, 2013) as variações nas taxas de juros e câmbio (Oliveira, Ramalho \& Moura, 2013), o mercado de capitais pouco desenvolvido e, ainda, a baixa qualificação do empresário e dos tomadores de decisão (Carvalho \& Schiozer, 2012).

Em função das especificidades brasileiras, desenvolveu-se teoricamente o Modelo Dinâmico do Capital de Giro ou, também conhecido por Modelo Fleuriet entre as décadas de 1970 e 1980 (Braga, 1991) (Marques \& Braga, 1995). Neste modelo, os ativos e passivos circulantes são reclassificados segundo sua natureza: errática e cíclica.

Medeiros e Rodrigues (2004) questionaram a validade do Modelo Fleuriet a partir de um estudo empírico no Brasil. No entanto, outros trabalhos abordaram o método com amostras amplas e estudos de caso e concluíram pela validade e/ou utilidade do modelo (Gimenes \& Gimenes, 2008) (Starke, Freitag \& Cherobim, 2008) (Rodrigues, Moura \& Santos, 2011) (Nascimento et al., 2013) e (Jones \& Jacinto, 2013).

Neste corolário de discussões recentes quanto a influência do investimento empresarial no capital de giro e a aplicabilidade do Modelo Fleuriet para o gerenciamento dos recursos correntes das empresas, identificou-se uma lacuna teórico-empírica não abordada nos últimos estudos de maior abrangência e impacto no que diz respeito à influência segregada dos investimentos não circulantes no capital de giro (Mongrut, Fuenzalida, Cubillas \& Cubillas, 2014) (Palombini \& Nakamura, 2012) e (Almeida \& Eid, 2014).

Depois da aderência do Brasil às normas internacionais que resultaram na adoção das práticas da International Financial Reporting Standarts (IFRS) em 2005, as empresas com títulos mobiliários negociados em bolsa de valores passaram a classificar os investimentos em Circulantes 
e Não Circulantes, sendo que neste último, devem constar quatro grupos de contas, a saber: Realizável a Longo Prazo (RLP), Investimento (INV), Imobilizado (IMOB) e Intangível (INT).

Desta forma, a questão que motivou a proposição deste projeto de pesquisa foi: qual o impacto dos diferentes investimentos de longo prazo na dinâmica do capital de giro das empresas instaladas no Brasil?

O problema torna-se relevante tanto para a academia quanto para o meio empresarial, tendo em vista que não foram encontrados na revisão teórica inicial nas principais bases de dados (ISI, Scopus, Ebsco e Scielo) estudo equivalente no Brasil ou no exterior. As pesquisas existentes utilizam, apenas, os investimentos fixos (imobilizados) ou o ativo não circulante total. Todavia, as características distintas destas contas, sugerem inicialmente, que exerçam diferentes graus de influência na dinâmica do capital de giro das empresas. Além disso, sabe-se, que a análise não pode ser feita somente de forma agregada, pois as características dos setores influenciam o ciclo financeiro das organizações.

Importa ressaltar a preponderância deste estudo, também, para o meio empresarial em função da representatividade econômica que o capital de giro tem na estrutura patrimonial das empresas (Assaf, 2005) e no efeito de melhorar o planejamento financeiro das organizações.

Assim, o principal objetivo deste estudo é analisar o impacto dos investimentos de longo prazo na dinâmica do capital de giro das empresas brasileiras.

Para alcançar o objetivo proposto, este estudo foi dividido em mais quatro seções, a partir desta introdução. A segunda seção apresenta os fundamentos teóricos que suportaram a construção do modelo empírico para análise. Na sequência são apresentados os Materiais e Métodos que permitiram a realização da pesquisa. Os resultados e discussões integram a quarta seção que é seguida pelas considerações finais. As referências utilizadas estão elencadas no final do artigo.

\section{REFERENCIAL TEÓRICO}

Para Assaf (2005) o termo capital de giro refere-se aos recursos de curto prazo da empresa. Dessa forma, o capital de giro (CG) é denominado como a parcela do capital da empresa que está disponível para aplicações e, relaciona-se aos recursos que circulam na empresa no intervalo de tempo compreendido como ciclo operacional.

Zouain et al. (2011) explicam que o capital de giro é representado pelo ativo circulante, que por sua vez, é caracterizado como as aplicações correntes (Disponibilidades, Contas a receber e Estoques) das empresas, que são ativos capazes de serem transformados em dinheiro com mais facilidade e rapidez (Brealey, Myers \& Marcus, 2002). Outra definição para CG pode ser o conjunto de recursos demandados por uma empresa para financiar suas necessidades operacionais, compreendendo desde a aquisição de matérias primas até o recebimento pela venda do produto final.

Assaf (2005) afirma que o CG tem participação relevante no desempenho operacional das empresas, sua gestão eficiente ameniza e evita fatores como redução de vendas, crescimento da inadimplência, aumento das despesas financeiras e aumento de custos. Também assegura que os 
recursos sejam suficientes para continuar as operações sem interrupções custosas, completam Ross, Westerfield e Jordan (2000).

Além do Ciclo Operacional, a necessidade de capital de giro é influenciada pelo Ciclo de Caixa, ou Ciclo Financeiro (CF) da empresa. Segundo Berk et al. (2010) o CF compreende o período entre o pagamento dos fornecedores pela aquisição da matéria prima até o momento em que a empresa recebe o pagamento pela venda do produto. Quanto mais longo for o CF da empresa mais capital de giro ela demandará, incluindo disponibilidades de caixa para atender suas obrigações de curto prazo.

As contas de ativos são definidas por Frezatti, Bido, Cruz, Barroso e Machado (2012) como os recursos da empresa resultantes de eventos passados e que irão gerar benefícios econômicos futuros. Os ativos se dividem em ativos de curto prazo (circulante) e ativos de longo prazo (nãocirculantes).

Os ativos de longo prazo (Intangíveis, Imobilizados e Realizável à longo prazo) por sua vez, podem apresentar risco de retorno e dificuldade de quantificar seu benefício esperado em consequência do prazo para realização dos resultados futuros (Frezatti et al., 2012). Por isso, os investimentos, em especial os de longo prazo, devem ser bem analisados, buscando focar oportunidades de aplicação que apresentem valor superior à sua aquisição e o custo de oportunidade que os encerram; esse processo de planejamento e gerenciamento a longo prazo é denominado, orçamento de capital (Ross et al., 2000).

Para manter o equilíbrio financeiro, as necessidades financeiras permanentes e de longo prazo devem ser financiadas por recursos de longo prazo, enquanto que as necessidades variáveis (circulantes) devem ser financiadas com fontes de curto prazo (Zouain et al., 2011).

A estrutura financeira da empresa é composta pela combinação entre o capital de terceiros (financiamentos e passivos operacionais) e o capital próprio que a mesma usa para financiar suas operações (Ross et al., 2000).

A política de capital de giro deve considerar o trade-off existente entre rentabilidade e liquidez pois as empresas com uma política de capital de giro mais agressiva em investimento devem apresentar maiores índices de retorno, porém estão mais sujeitas aos problemas de liquidez e insolvência do negócio (Almeida \& Eid, 2014).

Existem inúmeras pesquisas sobre as decisões de investimento e a relação entre investimento e valor da empresa. Alguns trabalhos, como seminal de Modigliani e Miller (1958), mostram que as decisões de investimento e de financiamento são independentes entre si (BañosCaballero et al., 2014). Outros estudos sobre decisões de investimento e financiamento à longo prazo mostram que os ativos de curto prazo são importantes para o balanço patrimonial das empresas e precisam de dedicação por parte dos gestores na gestão do capital de giro para encontrar o equilíbrio entre realizáveis e exigíveis de curto prazo (Palombini \& Nakamura, 2012).

Fatores internos e externos das empresas podem influenciar suas decisões em relação à mensuração do nível ideal de ativos e passivos correntes. Os gestores podem levantar capital para um investimento usando uma política agressiva de capital de giro ou ainda diminuir os estoques. Discutir os fatores da gestão de capital de giro não é simples. Os estudos focam em sua maioria, as 
relações do capital de giro com a rentabilidade da empresa, que cria valor para o acionista (Palombini \& Nakamura, 2012).

No Brasil, a eficiência na gestão do capital de giro é relevante para as empresas devido ao custo elevado de empréstimos de curto prazo e as dificuldades para obter financiamento para as necessidades de capital de giro permanentes. Segundo Palombini e Nakamura (2012) os gestores financeiros devem buscar equilíbrio entre o risco, o retorno e a liquidez, a fim de criar valor para a empresa.

O investimento em capital de giro depende das condições de financiamento da empresa pois este é mais sensível às restrições de financiamento do que os ativos fixos (Baños-Caballero et al., 2014). De acordo com Brealey et al. (2002), o CG depende, também, do nível de atividades da empresa, ou seja, quanto maior o seu investimento em ativos de longo prazo, maior será a sua necessidade de capital de giro e, com efeito, maior será sua necessidade de financiamento. A eficiência na gestão do CG aloca de forma correta os investimentos na necessidade de capital de giro, provendo a liquidez necessária para o ciclo operacional, porém sem excedentes o que permite novos investimentos e amplia a flexibilidade financeira da empresa (Almeida \& Eid, 2014).

O investimento em CG pode acarretar alguns impactos negativos como o aumento de custos de manutenção do Estoque disponível, aumento dos custos de financiamento para suprir o aumento na necessidade de capital, aumento de despesas e de dificuldades financeiras. Além disso, em ambiente de restrição de capital, a destinação de recursos no capital de giro, "que não gira" implica na redução de investimentos em projetos não circulantes que poderiam incrementar o desempenho empresarial (Baños-Caballero et al., 2014).

De acordo com Assaf (2005), a diferença entre o ativo e o passivo circulantes resulta em um volume chamado de Capital Circulante Líquido (CCL) que é um indicador de liquidez da empresa. Oliveira et al. (2013) completam que no caso de $C C L>0$ a empresa é capaz de cumprir suas obrigações de curto prazo com sobra financeira; se o $C C L=0$ tudo o que a empresa produz é usado para quitar as obrigações de curto prazo e; se o $\mathrm{CCL}<0$ a empresa não consegue sanar todas as suas obrigações de curto prazo e esgota suas fontes de financiamento operacionais. Quanto maior o CCL, melhor é a liquidez de curto prazo, também conhecida como suficiência financeira. Porém a avaliação da liquidez somente pelo CCL da empresa é insatisfatória pois considera apenas as características operacionais da mesma, sem considerar o aspecto da eficiência, ou seja, a distribuição adequada de recursos entre os investimentos de curto prazo.

A capacidade da empresa de cumprir com suas obrigações financeiras no prazo determinado e sem alterar suas operações normais é chamada de liquidez corrente (LC) e pode ser verificada através da fórmula (Guimarães \& Nossa, 2010):

$$
L c=\frac{\text { Ativo circulante }}{\text { Passivo circulante }}
$$

Loncan e Caldeira (2014) listam 4 motivos para que as empresas mantenham liquidez: diminuir os custos de transação (manter um volume de ativos correntes para quitar pagamentos dentro do prazo), por precaução (para conseguir sobreviver sem recorrer à financiamentos externos de alto custo), impostos (para aliviar a carga fiscal de repatriação dos lucros obtidos em 
operações externas, no caso de empresas multinacionais) e por oportunidade de investimento (manter caixa para negociar).

Diante disso a primeira hipótese desse estudo é a influência significativa e positiva da variação no investimento no volume de recursos dedicados a liquidez.

Segundo Fonseca e Ceretta (2012) o nível ideal de liquidez é uma questão não solucionada na teoria financeira, tendo poucos estudos focados em identificar a proporção de ativos que devem possuir liquidez para a manutenção de atividades. A gestão do CG complementa a teoria financeira, reforçando que é preciso saber quais recursos (próprios e de terceiros) foram utilizados e também o prazo de rotação de cada um deles.

O principal objetivo dos gestores financeiros é criar valor para os acionistas da empresa no longo prazo. A análise financeira convencional, realizada através de balanços e índices de liquidez, considera um elevado número de variáveis e a estrutura de apresentação contábil não reflete a condição econômica financeira da firma, em consequência, há conflitos teóricos e práticos que enviesam a avaliação. Para apurar melhor as atividades da empresa e analisar se os recursos gerados superam os recursos consumidos pode-se utilizar o Modelo Fleuriet (MF), que traz indicadores da dinâmica das operações da empresa através da análise dos ciclos financeiro e operacional (Camargos, Camargos \& Leão, 2014).

Para Guimarães e Nossa (2010), a gestão do CG deve ser feita com base em uma análise de risco-retorno que considere a relação entre o montante de recursos no ativo operacional e a rentabilidade da empresa. Existem diversos trabalhos desenvolvidos com foco na liquidez e sua mensuração, porém a relação rentabilidade $x$ liquidez proposta pelo Modelo de Fleuriet busca analisar a capacidade da empresa em cumprir as obrigações, levando em consideração a continuidade de suas operações. Enquanto o uso de índices de liquidez é visto por alguns autores como estático e sem conteúdo informacional necessário para cumprir o objetivo pretendido, o MF é mais sensível à alterações financeiras da empresa e ainda classifica seu desempenho.

O MF é um método muito difundido no Brasil e na França, porém não é usado ou tão difundido em outros países. Ele faz uso dos três ciclos da empresa: o ciclo financeiro ou de conversão de caixa, operacional e ciclo econômico (Guimarães \& Nossa, 2010).

Guimarães e Nossa (2010) explicam que o MF divide as contas da empresa em contas de curto prazo (erráticas), contas operacionais (cíclicas) e contas de longo prazo. O primeiro grupo é formado por contas de natureza financeira, ou seja, Caixa e equivalentes, empréstimos e outras obrigações financeiras, como o pagamento de dividendos. O segundo grupo é formado por contas que envolvem operações da empresa, logo, os ativos que não são financeiros. O terceiro grupo, por sua vez, é formado por contas de longo prazo como os ativos imobilizados, obrigações de LP e patrimônio. Essa reclassificação das contas da empresa permite calcular e determinar melhor a estrutura financeira da mesma quanto a sua posição de liquidez.

Apesar da disseminação brasileira do MF, Camargos et al. (2014) encontraram estudos que contestam a separação dos ativos em erráticos (ACF) e cíclicos (ACO) como o de Medeiros e Rodrigues (2004) e de Starke et al. (2008), que defendem que os ACF interferem nas operações da empresa, portanto também são operacionais, hipótese confirmada em suas pesquisas através da comprovação da relação entre a receita operacional líquida e o ativo corrente. Embora a distinção 
entre ACF e ACO tenha sido questionada nos estudos citados pelo autor, as contas operacionais são capazes de explicar de forma mais abrangente a variabilidade das operações da empresa.

O próprio Fleuriet (2005) argumenta que seu modelo objetiva explorar e financiar a gestão de desempenho o que explica a diferenciação das contas em ciclos empresariais. Essa separação dos ciclos facilita a identificação dos riscos decorrentes das deficiências dos balanços das empresas.

Fonseca e Ceretta (2012) afirmam que o MF desenvolve os três conceitos abaixo para a análise dinâmica das empresas:

i. Saldo de Tesouraria (ST) - é obtido pela diferença entre o ativo e o passivo circulante, ou ainda, pela diferença entre NCG e CG. Se for negativo significa que o CG não consegue financiar o ativo permanente e as atividades de curto prazo, o que pode aumentar o risco de sobrevivência da empresa.

ii. Necessidade de Capital de Giro (NCG) - obtida pela diferença entre ativo e passivo operacionais, é a necessidade de recursos financeiros para manter o ativo operacional mediante à incompatibilidade de datas de entrada e saída de capital.

iii. Capital de Giro (CG) - já definido anteriormente, é uma fonte de recursos de longo prazo proveniente de empréstimos bancários para ser aplicada no ativo circulante e usado quando o NCG da empresa é positivo.

\begin{tabular}{ll|}
\hline$A C F-P C F=S T$ & $(01)$ \\
$A C O-P C O=N C G$ & $(02)$ \\
$A C-P C=C C L$ & $(03)$ \\
\hline
\end{tabular}

Figura 1: Fórmulas das variáveis do Modelo Fleuriet. Fonte: elaborado pelos autores.

A Figura 1 traz as fórmulas para encontrar os conceitos explicados. A partir desses conceitos Nascimento et al. (2013) identificam padrões e estratégias de investimento / financiamento que podem ser distribuídas em seis tipos de perfil, conforme a Figura 2.

No perfil Tipo I, de situação financeira Excelente, a empresa apresenta alto nível de liquidez uma vez que os recursos não circulantes estão aplicados nos ativos de curto prazo e o ACO > PCO. Qualquer alteração na receita da empresa pode tornar o ST negativo, o que caracteriza a dependência das vendas. No perfil Tipo II, o CG é suficiente para a NCG e ainda sobram recursos. No Tipo III, de situação financeira Insatisfatória, a empresa apresenta CG < NCG e precisa de recursos de curto prazo para suprir as atividades operacionais.

O perfil Tipo IV, considerado de situação financeira péssima, engloba empresas com dificuldade de cumprir as obrigações assumidas pois seus recursos de curto prazo financiam a NCG e o ativo permanente. No perfil Tipo V, o PCO consegue financiar o ACO mesmo com a NCG e o ST negativo. A situação financeira de Alto Risco, perfil Tipo $\mathrm{VI}$, ocorre quando a empresa financia os ANC com recurso de curto prazo. Quando redução nas vendas esgotaria os recursos deixando o ST negativo (Nascimento et al., 2013). 


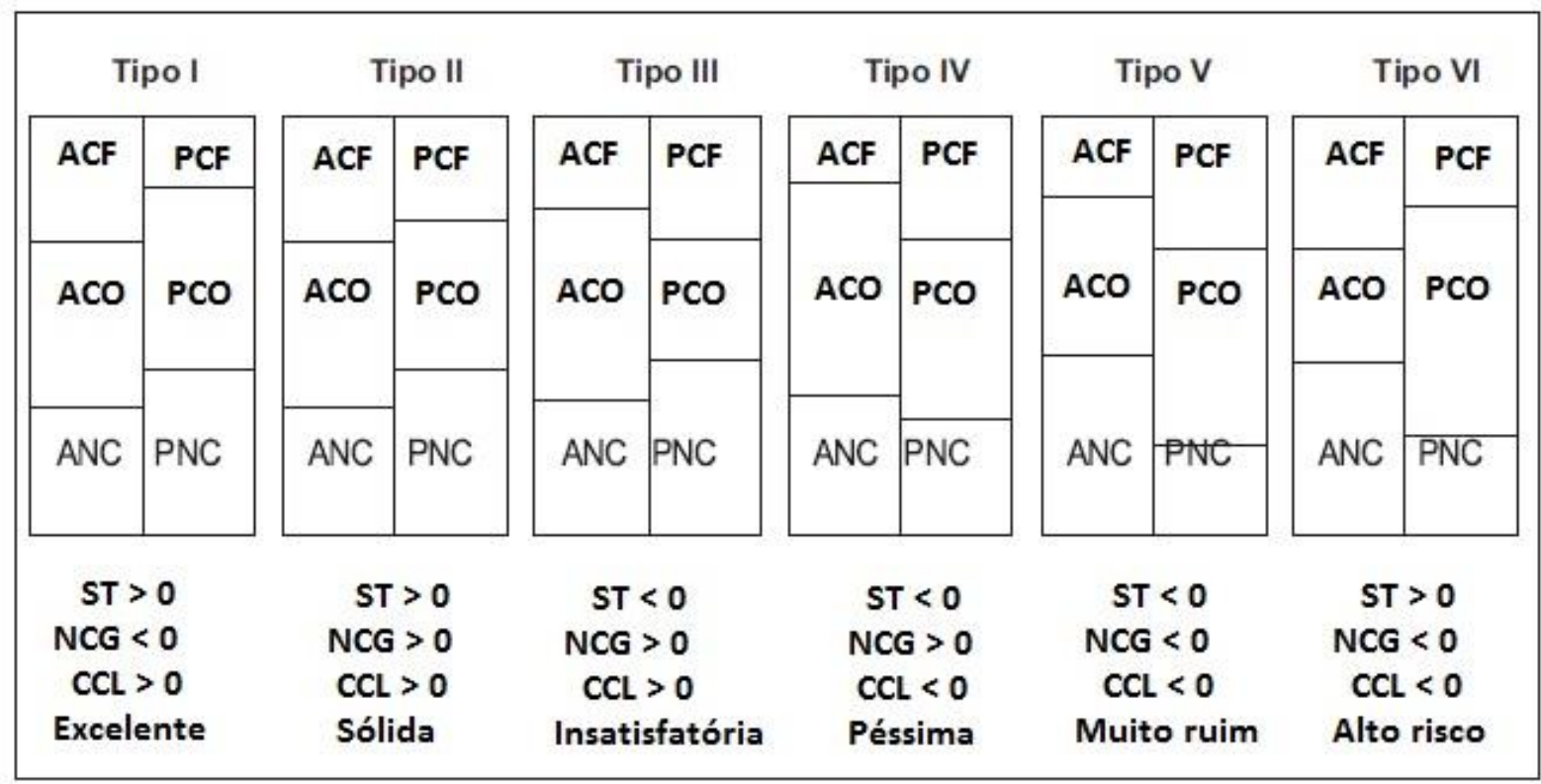

Figura 2: Tipos de situação financeira.

Fonte: adaptado de Braga (1991, p. 11 e 12)

Guimarães e Nossa (2010) completam que o perfil do Tipo I é o mais desejável pois possui CG positivo é melhor liquidez que os outros perfis. Fleuriet (2005), por sua vez, afirma que se a NCG for sazonal, é interessante para a empresa manter ST, porém, se a NCG apresentar aumento permanente o capital de giro deve ser financiado por uma fonte de recurso de longo prazo para não esgotar a liquidez da empresa.

De acordo com Camargos et al. (2014), o ST elevado e positivo não significa necessariamente que uma situação favorável para empresas, pois pode sinalizar que as mesmas não estão aproveitando oportunidades de investimento, ou seja, o ST elevado pode indicar falta de estratégia de investimentos.

Nos diversos estudos realizados até o momento sobre gestão do capital de giro, encontrase uma prevalência de análises tradicionais com base na contabilidade da empresa, sendo poucos os estudos que envolvam análise pelo MF.

Segundo Almeida e Eid (2014), é preciso considerar todos os aspectos da gestão do capital de giro pois eles se influenciam simultaneamente para avaliar o valor da empresa. Nascimento et al. (2013) afirmam que o MF explica de forma mais completa e organizada as causas da evolução financeira das empresas.

De acordo com Fonseca e Ceretta (2012) uma pesquisa feita por Weinraub e Visscher (1998) envolvendo 216 empresas por 10 anos, mostrou que as empresas tendem a balancear suas estratégias de investimento de curto prazo, ou seja, aplicam uma estratégia agressiva em uma área (passivo ou ativo) e compensam com uma estratégia conservadora em outra área. Perobelli, Pereira e David (2006), estudaram a relação entre rentabilidade e liquidez através do retorno contábil (ROE) em empresas siderúrgicas e lojas de departamento, e concluíram que há uma correlação inversa entre rentabilidade e liquidez nas mesmas. Uma análise de 8.872 pequenas e médias empresas espanholas dos anos de 96 a 2002, feita por Teruel e Solano (2009), verificou, 
através da relação entre a gestão do CG e a rentabilidade (obtida com o ROA), que reduzir prazo de recebimento de contas, reduzir tempo de ciclo de conversão de caixa e reduzir tempo de estoque melhoram a rentabilidade da empresa, criando valor para a mesma.

Outros estudos ainda são citados por Fonseca e Ceretta (2012), como, o de Marques e Braga (1995) onde os índices da análise tradicional foram comparados aos índices do MF e dessa forma concluiu-se que o MF pode indicar antecipadamente situações de deterioração e recuperação financeira, não demonstradas pelo meio tradicional.

Estudos realizados por Silva, Botelho e Ferreira (2009) com empresas metalúrgicas brasileiras para estimar a influência da liquidez sobre o lucro líquido empresarial considerando o NCG e o ST, mostraram que o NCG precisa ser positivo e que os resultados eram insatisfatórios quando o ST era negativo. Paixão, Bruni, Murray e Garcia (2008) estudaram empresas do setor comercial no período de 2002 a 2004 para analisar a gestão de CG e encontraram o perfil Tipo IV na maioria delas, caracterizado como NCG positiva e ST negativa, o que demonstra que há necessidade de obtenção de recursos onerosos a curto prazo para este setor (Nascimento et al., 2013).

Assim, há um coletivo de pesquisas acadêmicas sobre a gestão do capital de giro concentrados no escopo da influência do capital de giro no desempenho financeiro ou econômico das empresas, poucos são os estudos que estenderam essa análise aos efeitos das estratégias de investimento na gestão do capital de giro.

\section{METODOLOGIA}

Para realização desta pesquisa, propôs-se uma abordagem metodológica quantitativa com fins descritivos para análise da influência dos investimentos empresariais no capital de giro das empresas.

\subsection{Materiais}

Os materiais utilizados nesta pesquisa foram os dados financeiros publicados nas Demonstrações Financeiras Padronizadas das empresas de capital aberto. Sabe-se que as empresas de capital aberto devem publicar seus balanços trimestralmente e estes devem ser auditados por empresa especializada independente e autorizada pela Comissão de Valores Mobiliários.

Essa amostra limita o alcance da pesquisa para a realidade brasileira, tendo em vista, que a BM\&FBOVESPA computa menos de 400 empresas listadas, frente as mais de 5,1 milhões de pessoas jurídicas existentes no Brasil em janeiro de 2016.

Todavia, para a realização desta pesquisa, em conformidade com os objetivos pretendidos, houve a necessidade da disponibilidade de informações contábeis financeiras trimestrais e que estas fossem confiáveis. Portanto, a amostra para a realidade brasileira está composta por empresas de capital aberto na BM\&FBOVESPA, cujos dados foram coletados por meio do Sistema Economática ${ }^{\circledR}$. 
O período para análise compreendeu os anos 2011 a 2014 e os dados foram tomados trimestralmente, assim, foram tabuladas, a princípio, dezesseis demonstrações financeiras por empresa. O início em 2011 deve-se a partida para as publicações das empresas instaladas no Brasil no modelo do International Financial Reporting Standards (IFRS). Ressalta-se que como se trata de uma análise longitudinal, foram utilizadas somente as empresas que apresentaram informações em todos os períodos, logo foram excluídas:

a. Empresas extintas durante o período por processos de fusão, incorporação ou liquidação;

b. Empresas que ingressaram no mercado de capital no curso do período em análise;

c. Além destas, não foram computadas as seguintes entidades para não enviesar a análise, em função de características operacionais não correntes;

d. Empresas com falência decretada ou em recuperação judicial não julgada;

e. Empresas em estágio pré-operacional, isto é, sem apuração de receita.

A estratificação das empresas por segmento obedece ao critério americano (NAICS) amplamente utilizado nos estudos empíricos da área financeira, com destaque, para os trabalhos publicados no exterior (Almeida \& Eid, 2014).

As identidades das variáveis de interesse estão dispostas nas Equações 4 a 09.

\begin{tabular}{|lc|lc|}
\hline \multicolumn{2}{|c|}{ Variáveis de Capital de Giro } & \multicolumn{1}{|c|}{ Variáveis de Investimento } \\
\hline$N C G=A C O-P C O$ & $(04)$ & $\Delta R L P=\left(R L P_{t}-R L P_{t-1}\right) / R L P_{t-1}$ & (06) \\
\hline$S T=A C F-P C F$ & $\Delta I N V=\left(I N V_{t}-I N V_{t-1}\right) / I N V_{t-1}$ & (07) \\
\hline & $\Delta I M O B=\left(I M O B_{t}-I M O B_{t-1}\right) / I M O B_{t-1}$ & (08) \\
\hline & $\Delta I N T=\left(I N T_{t}-I N T_{t-1}\right) / I N T_{t-1}$ & (09) \\
\hline
\end{tabular}

Fonte: (Assaf Neto, 2005) (Berk, Demarzo, \& Harford, 2010).

Inicialmente foram encontradas 380 empresas para compor a amostra, porém foram excluídas aquelas que se encontravam nos critérios de seleção descritos (extintas após fusão, empresas em falência, etc.). Após um teste inicial da amostra, decidiu-se por excluir também empresas que não apresentavam informações financeiras em mais de $50 \%$ dos períodos, pois a ausência de dados poderia influenciar na análise da amostra total, essa exclusão resultou uma nova amostra com 290 empresas.

Instituições financeiras e empresas de participações também foram retiradas da amostra pois as instituições financeiras possuem um giro diferente das demais empresas e as empresas de participações apresentam uma estrutura de negócio distinta dos setores industriais, comércio, serviço e agrícola. Assim, a amostra final resultou em 255 empresas.

Para otimizar a análise e gerar resultados mais relevantes, a amostra foi segmentada por tamanho. Determinou-se a mediana dos ativos totais das empresas e a amostra foi dividida em: 
Amostra 1 (com valores de Ativos Totais acima da mediana) e Amostra 2 (com empresas cujos valores dos Ativos Totais estavam abaixo da mediana).

Ainda assim, a dispersão dos dados continuou gritante, dificultando a análise. Foi proposto então a divisão da amostra por segmento empresarial, de acordo com a classificação NAICS. Devido a quantidade de empresas por setor, optou-se por analisar dois grupos, de empresas comerciais e industrias, porém isso não reduziu a dispersão.

Após o retorno da análise não ser satisfatório, as variáveis foram padronizadas, ou seja, foi realizada a diferença de cada observação pela média cujo resultado foi dividido pelo desvio padrão, o que torna uma série com média igual a 0 (zero) e desvio padrão igual a 1 (um).

Foi incluída também a primeira diferença das variáveis de interesse de capital de giro pois em séries temporais, os valores futuros podem ser determinados por valores passados e, isso é possível de ocorrer nos indicadores de capital de giro, em razão deles representarem um ciclo financeiro que se estende no tempo (Assaf\& Silva, 2010).

\subsection{Métodos}

Após a conclusão da base de dados e o cálculo de todas as variáveis, os seguintes procedimentos metodológicos foram empregados para análise:

1. Cálculos estatísticos descritivos tradicionais referentes as medidas de posição (média e mediana) e dispersão das variáveis (variância, desvio padrão e coeficiente de variação) em conformidade com (Bussab \& Morettin, 2003).

2. Cálculo do coeficiente de correlação entre as variáveis de investimento e capital de giro, por meio do Coeficiente de Pearson, conforme Equação 10.

$$
p_{(x, y)}=\frac{\sum x_{i} y_{i}-n \bar{x} \bar{y}}{\sqrt{\left(\sum x_{i}^{2}-n \bar{x}^{2}\right)\left(\sum y_{i}^{2}-n \bar{y}^{2}\right)}}
$$

3. Verificação da influência das variações nos investimentos na dinâmica do capital de giro por modelo de regressão linear com painel em dados, sendo esta técnica utilizada por diferentes estudos na área (Palombini \& Nakamura, 2012) (Almeida \& Eid, 2014) (Mongrut et al., 2014). A importância dessa técnica deve-se a sua capacidade de combinar igualmente dados transversais com longitudinais o que garante o maior número de observações e a possibilidade de captar diferenças por unidades de observação ou pelo tempo (Gujarati, 2006). As Equações 11 e 12 apresentam os modelos empíricos a serem analisados.

$$
\begin{aligned}
& \Delta S T_{i t}=\beta_{i}+\Delta N C G+\Delta R L P_{i t}+\Delta I N V_{i t}+\Delta I M O B_{i t}+D i f_{-} S T_{i t}+\varepsilon_{i t} \\
& \Delta N C G_{i t}=\beta_{i}+\Delta S T+\Delta R L P_{i t}+\Delta I N V_{i t}+\Delta I M O B_{i t}+D i f_{-} N C G_{i t}+\varepsilon_{i t}
\end{aligned}
$$

Foram utilizados os modelos com efeitos fixos, pois considera-se que cada empresa é uma entidade autônoma no seu processo decisório, com efeito, os resultados por observação não são 
aleatórios, inclusive, como há um processo de aprendizado dentro das organizações, as decisões anteriores afetam o processo decisório seguinte.

Com o uso do modelo de efeitos fixo, deixou-se a constante somente com o subscrito " $\mathrm{i}$ " de empresa para captar a diferença na gestão de cada organização (Gujarati, 2006). Entretanto, se houver heteroscedasticidade, será empregado o método mínimos quadrados ponderados para corrigir ausência de homocedasticidade. Os procedimentos estatísticos de verificação de ajuste do modelo associados a: normalidade dos resíduos e das variáveis, ajuste das variáveis do modelo e autocorrelação dos resíduos serão analisados conforme as exigências teóricas (Gujarati, 2006).

Os dados coletados foram transportados para planilhas eletrônicas do Microsoft Excel ${ }^{\circledR} \mathrm{e}$ depois submetidas ao Software GRETL 1.9.0 onde foram realizados os tratamentos estatísticos, incluindo a regressão com dados em painel. $O$ ajuste das contas em Cíclicas e Erráticas permitiu o cálculo do ST e no NCG em todos os períodos a serem estudados. Cada variável de Capital de Giro e de investimento de Longo Prazo passou por cálculos de variação de um período (trimestre) em relação ao anterior, gerando 15 observações por empresa.

\section{ANÁLISE DE RESULTADOS}

Com o objetivo de analisar o impacto dos investimentos de longo prazo no capital de giro das empresas brasileiras, esta seção apresenta inicialmente os resultados descritivos das variações das contas previstas no modelo empírico e que estão apresentadas na Tabela 1.

Tabela 1: Resultados descritivos

\begin{tabular}{c|r|r|r|r}
\hline \multicolumn{5}{c}{ Estatísticas descritivas (total de 3825 dados) } \\
\hline $\begin{array}{c}\text { Variável } \\
\text { (variação) }\end{array}$ & \multicolumn{1}{c}{ Média } & Mediana & Desv. Padrão & C.V. \\
\hline ST & $-67,80 \%$ & $-4,41 \%$ & $3.909,10 \%$ & $5.765,30 \%$ \\
\hline NCG & $-58,94 \%$ & $-0,73 \%$ & $3.204,90 \%$ & $5.437,30 \%$ \\
\hline RLP & $13,11 \%$ & $0,06 \%$ & $197,93 \%$ & $1.510,20 \%$ \\
\hline INV & $1.356,10 \%$ & $-1,11 \%$ & $50.747,00 \%$ & $3.742,10 \%$ \\
\hline IMOB & $11,84 \%$ & $-0,61 \%$ & $492,75 \%$ & $4.162,40 \%$ \\
\hline INT & $185,67 \%$ & $-1,20 \%$ & $8.193,50 \%$ & $4.413,10 \%$ \\
\hline
\end{tabular}

Observa-se que a variação média do ST foi negativa, caracterizando à redução de liquidez das empresas que alcançou os últimos trimestres em análise com ST médio negativo, o que denota para a ausência de recursos erráticos frente aos empréstimos de CP.

Nota-se, também, que há uma redução média na NCG o que constata a redução da atividade econômica no país no período analisado. Com ambas as variáveis de CG (ST e NCG) apresentando variação média negativa, a situação financeira das empresas pode ser considerada 
muito ruim (Braga, 1991) (Nascimento et al., 2013) uma vez que relata a participação de fontes de CP financiando investimentos de LP, sendo ainda, a NCG negativa.

Dentre as variáveis que reportam os investimentos empresariais em longo prazo, nota-se, crescimento médio em todas as variáveis, sendo que, contudo, o comportamento mediano é negativo o que denota que $50 \%$ da amostra teve crescimento médio negativo de ativos e a segunda metade retração.

A dispersão de resultados é evidente para todas as variáveis e confirma a heterogeneidade das empresas no Brasil, mesmo àquelas listadas no Mercado de Capitais (Palombini \& Nakamura, 2012). INV apresentou maior variação média, mas também possui maior desvio padrão. Essa elevada dispersão traz problemas no tratamento estatístico, em função, da necessidade de normalidade nas séries.

O crescimento marginal expressivo da conta Investimento, em comparação às demais, deve ser ressalvado em função de dois aspectos: i) trata-se de uma conta com menor valor médio entre as demais; e ii) são contabilizados investimentos em empresas coligadas/controladas, assim como, em fundos de investimentos, sendo essas contas mais dinâmicas quanto as movimentações de participação e o próprio valor de mercado. Portanto, as variações percentuais são mais expressivas.

Em função dessa característica e dispersão, essa conta de Investimento não foi computada, pois não está diretamente associada aos investimentos fixos (tangíveis e intangíveis) das empresas.

Em seguida, foi realizada a análise de correlação entre as variáveis de interesse, para identificar o quanto cada uma exerce influência na outra, cujos resultados estão expostos na Tabela 2.

Tabela 2: Matriz de correlação entre as variáveis

\begin{tabular}{c|c|c|c|c|c|c|c}
\hline \multicolumn{7}{c}{ Coeficientes de Correlação (observações 1:001 - 15:255) } \\
\hline \multirow{2}{*}{ ST } & \multirow{2}{*}{ NCG } & RLP & IMOB & INV & Dif_ST & Dif_NCG & Variáveis \\
\hline 1 & $-0,0074$ & $-0,0154$ & 0,0088 & $-0,0015$ & 0,7059 & $-0,0031$ & ST \\
\hline & 1 & $-0,0005$ & $-0,0055$ & 0,0091 & $-0,0038$ & 0,7094 & NCG \\
\hline & & 1 & 0,0555 & 0,0696 & $-0,0091$ & $-0,0004$ & RLP \\
\hline & & & 1 & 0,1695 & 0,0045 & $-0,00509$ & IMOB \\
\hline & & & & 1 & 0,0004 & 0,0194 & INT \\
\hline & & & & & 1 & $-0,0049$ & Dif_ST \\
\hline & & & & & & 1 & Dif_NCG \\
\hline
\end{tabular}

Fonte: elaborada pelos autores.

As variações das contas de capital de giro apresentam forte correlação com suas respectivas 1as Diferenças, que como já foi explicado, caracterizam relevante influência das variáveis sobre os seus valores posteriores. 
As demais correlações observadas não apresentam valores expressivos que permitam assegurar forte grau de associação. Essa característica é importante para evitar problemas de multicolinearidade entre as variáveis (Gujarati, 2006). Por outro lado, mostram, inicialmente, que os investimentos em ativos não estão associados diretamente com as variáveis do MF como era esperado.

Depois de empreender as regressões propostas nas equações 08 e 09, através do modelo de efeitos fixos, verificou-se a presença de heretoscedasticidade, em função, das elevadas variâncias entre as empresas. Para corrigir esse erro foram providenciadas análises dos outliers onde os valores que superavam 3 desvios padrões em adição ou subtração a média foram substituídos pela média e na sequência as variáveis foram padronizadas, a partir da divisão da diferença entre a observação e a média pelo desvio padrão.

Mesmo com estes procedimentos, ainda foi detectada a presença de heteroscedasticidade pelo teste de Bresuch-Pagan nas duas regressões. Desta forma, foi utilizado o método de mínimos quadrados ponderados como foram de corrigir o problema de presença de diferentes variâncias no curso da série, sendo este procedimento semelhante ao adotado por Palombini e Nakamura (2012) e coerente com a Literatura (Gujarati, 2006).

A Tabela 3 apresenta os resultados da regressão proposta na equação 08 para explicar a Variação no ST.

Tabela 3: Resultados da regressão para ST

\begin{tabular}{c|c|c|c|c|c}
\hline & Coeficiente & Erro Padrão & razão-t & $\boldsymbol{p}$-valor & Sig. \\
\hline const & 0,0168706 & 0,0013545 & 12,4552 & $<0,00001$ & $* * *$ \\
\hline 1ㄹ Dif_ST & 0,468464 & 0,0078784 & 59,4616 & $<0,00001$ & $* * *$ \\
\hline NCG & $-0,0011543$ & 0,00169215 & $-0,6822$ & 0,49519 & \\
\hline RLP & $-0,00175064$ & 0,00162863 & $-1,0749$ & 0,28248 & \\
\hline IMOB & 0,00505034 & 0,00156391 & 3,2293 & 0,00125 & $* * *$ \\
\hline INT & $-0,00118349$ & 0,00126078 & $-0,9387$ & 0,34795 & \\
\hline \multicolumn{2}{r|}{$R^{2}(0,499418)$} & \multicolumn{2}{c|}{ Estatística F $(5,3564)$} & valor $(0,00)$ \\
\hline
\end{tabular}

Notas: 1. Foram computadas 3.570 observações (255 empresas x 14 anos);

2. Variável Dependente: $\Delta \mathrm{ST}$;

3. $* * *, * *, *$ significam na estatística o nível de $1 \%, 5 \%$ e $10 \%$, respectivamente.

Fonte: elaborado pelos autores.

Nota-se que o modelo proposto para analisar o impacto dos investimentos no Saldo de Tesouraria apresentou ajuste aceitável, em função da capacidade de explicação do modelo $(49,94 \%)$ e a rejeição da hipótese nula na Estatística $F$ quanto a incapacidade das variáveis independentes em explicar a dependente. Esse resultado de ajuste confirma a eficiência do modelo exploratório quanto a proposição da variável de primeira diferença da variável independente, o que evidencia uma diferenciação importante neste trabalho.

A inclusão dessa variável deve-se ao reconhecimento teórico que os recursos empregados no ciclo do capital de giro não são aleatórios, mas há uma inércia na sua realização e, com efeito, 
uma transferência de valores dentro do giro financeiro em que as atividades ocorrem (Assaf \& Silva, 2010).

No entanto, o modelo apresentou restrições quanto ao ajuste estatístico para uso dos coeficientes para fins de estimação, pois foi constatada a presença de autocorrelação e ausência de normalidade dos resíduos (Gujarati, 2006).

Os resultados da Regressão na Tabela 03 apresentam uma informação que complementam a expectativa do trade-off esperado entre liquidez e rentabilidade. A explicação teórica aponta que a realização de investimentos implicaria na redução da disponibilidade de capital circulante líquido (Assaf, 2005; Baños-Caballero et al., 2014), no entanto, ao evidenciar que a variação no imobilizado exerce influência significativa na variação do saldo de tesouraria o trade-off precisa ser reanalisado. Esse resultado contrasta também o estudo de Mongrut et al. (2014) que encontraram para América Latina uma influência negativa entre investimento e capacidade de conversão de caixa em período anterior ao realizado neste estudo.

Não obstante, não é possível refutar a presença do trade-off, tendo em vista, que a variação anterior do saldo de tesouraria, também, é significativa para explicar o resultado futuro e o coeficiente desta variável é o mais elevado. Sendo assim, a maior folga financeira das empresas no presente é explicada pela maior disponibilidade de recursos erráticos no momento anterior, o que denota para um comportamento conservador das firmas brasileiras e confirma por outro modo a pesquisa de Baños-Caballero et al. (2014) que assinala para diferentes níveis ótimos de capital de giro em função do perfil de restrições financeiras da empresa.

Ressalta-se que a constante, também, foi significativa o que aduz para a existência de outras variáveis que explicam o comportamento do Saldo de Tesouraria, o que é natural, tendo em vista, que o escopo deste estudo se restringiu a análise dos investimentos não circulantes, sendo que as decisões de investimento e gestão do capital de giro envolvem outros fatores de gestão, conforme demonstrado por Frezatti et al. (2012), em especial, o alinhamento com o plano estratégico.

A terceira variável significativa para explicar o ST foi o do IMOB, sendo que o coeficiente positivo é próximo de zero. Como há a presença de autocorrelação e ausência de normalidade dos resíduos, foi analisado intervalo de confiança, considerando uma significância de 95\%; mesmo o coeficiente sendo próximo de zero, o intervalo foi muito estrito entre 0,0019844100 e 0,00811658 . Sendo assim, é possível assinalar que os investimentos em imobilizado exercem impacto positivo junto ao ST o que aponta para um comportamento conservador das entidades.

A Tabela 4 mostra os resultados da regressão proposta na equação 09, que explica a Variação na Necessidade de Capital de Giro.

Tabela 4: Resultados de regressão para NCG

\begin{tabular}{c|c|c|c|c|c}
\hline & Coeficiente & Erro Padrão & razão-t & p-valor & Sig. \\
\hline Const & $-0,00192276$ & 0,00127213 & $-1,5114$ & 0,13076 & \\
\hline Dif_NCG & 0,49587 & 0,0074659 & 66,4179 & $<0,00001$ & $* * *$ \\
\hline ST & $-0,00233148$ & 0,00145793 & $-1,5992$ & 0,10987 & \\
\hline RLP & 0,00288693 & 0,00136652 & 2,1126 & 0,0347 & $* *$ \\
\hline
\end{tabular}




\begin{tabular}{c|c|c|c|c|c} 
IMOB & 0,00486662 & 0,00187268 & 2,5987 & 0,0094 & $* * *$ \\
\hline INT & $-0,00088982$ & 0,00228348 & $-0,3897$ & 0,6968 & \\
\hline \multicolumn{2}{c|}{$\mathrm{R}^{2}(0,554276)$} & \multicolumn{2}{c}{ Estatística $\mathrm{F}(5,3564)$} & \multicolumn{2}{c}{ P-Valor $(0,00)$} \\
\hline
\end{tabular}

Fonte: elaborado pelos autores.

$\mathrm{Na}$ análise do impacto dos investimentos na Necessidade de Capital de Giro, o modelo proposto apresentou ajuste aceitável com capacidade de explicação das variáveis de $55,42 \%$, além da rejeição da hipótese nula na Estatística $\mathrm{F}$ quanto à incapacidade das variáveis independentes em explicar a dependente, o que demonstra a eficiência do modelo exploratório para analisar o impacto dos investimentos de longo prazo no capital de giro. Mais uma vez foi constatada a autocorrelação e a ausência de normalidade dos resíduos, o que dificultou a interpretação dos coeficientes para estimação.

Novamente três variáveis foram significativas para explicar as variações na NCG. Ressaltase que o ST poderia ser considerado significativo ao nível de $88 \%$, muito próximo ao limite mínimo convencional de $90 \%$. Sendo que o coeficiente negativo do ST sugere a existência do trade-off entre liquidez e rentabilidade.

O impacto positivo e significativo da NCG passada demonstra a inércia que as empresas têm em gerenciar o capital de giro, pois o resultado passado exerce influência no resultado presente (Assaf \& Silva, 2005). Essa situação pode ser explicada pelo próprio Ciclo Operacional das empresas, em que a formação de estoques pode implicar, no futuro, na geração de contas a receber, assim, as empresas devem gerenciar suas contas circulantes e operacionais com perspectiva de longo prazo (Mongrut et al., 2014). Apesar de encontrar subsídio teórico, os trabalhos empíricos não utilizam o resultado passado das variáveis financeiras de capital de giro como regressoras as variáveis de caixa ou ciclo de conversão de caixa, em especial, Palombini e Nakamura (2012) e Mongrut et al. (2014), por isso, os resultados alcançados com este modelo empírico pode trazer novas contribuições para esta relação.

Guimarães e Nossa (2010) contestaram a estrutura do capital de giro previstas por Braga (1991) demonstrando que é possível encontrar empresas com elevada rentabilidade, liquidez e solvência. Por outro caminho, este estudo demonstra que pode não existir um trade-off entre liquidez e rentabilidade, pois os investimentos no capital de giro não devem ser dissociados dos investimentos de longo prazo.

Importa observar que os investimentos em RLP, também, exercem impacto na NCG, considerando que as composições destas aplicações são ativos com a mesma natureza dos Ativos Circulantes Operacionais, porém com prazo de liquidez superior ao exercício, essa situação também era esperada e o entendimento é o mesmo que o efeito da diferença da NCG.

Igualmente ao ST, o IMOB exerce impacto positivo e significativo na NCG o que corrobora os pressupostos teóricos e práticos que a expansão dos investimentos fixos exerce impacto no Capital de Giro e neste caso de maneira ampliada, isto é, aumenta a NCG e o ST. Foi observado o intervalo de confiança desta conta com $95 \%$ do grau de confiança e os valores limites foram 0,00119498, e 0,00853825, assim, pode-se assinalar para o efeito positivo dos investimentos em imobilizado no capital de giro das empresas. 
Desta forma, apesar das restrições encontradas no modelo e que podem ser compreendidas em função das características heterogêneas das firmas brasileiras (Palombini \& Nakamura, 2012) (Almeida \& Eid., 2014), o modelo empírico utilizado foi capaz de analisar o impacto dos investimentos no capital de giro das empresas.

\section{CONSIDERAÇÕES FINAIS}

A motivação inicial deste estudo foi entender qual o impacto dos investimentos de longo prazo na gestão do capital de giro das empresas brasileiras e, para tanto, teve como objetivo analisar o impacto das diferentes formas que o investimento de longo prazo se apresenta no capital de giro, sendo este abordado pelo modelo dinâmico proposto por Fleuriet.

Diante dos resultados da pesquisa é possível para apontar para implicações teóricas e gerenciais que contribuem no melhor entendimento desta relação ainda não explorada plenamente em trabalhos empíricos.

A expectativa teórica da existência de trade-off entre liquidez e rentabilidade foi parcialmente refutada, pois foi possível evidenciar que os investimentos em ativos imobilizados exercem impacto positivo no ST e não negativo como deveria ser esperado. Em adição, a variação no ST que é um recurso errático tem a sua maior influência no seu valor anterior, deste modo, essas verificações sugerem para um comportamento conservador das empresas no tocante a gestão do ST.

Verificou-se, ainda, que os investimentos em ativos imobilizados influenciam no crescimento da NCG o que é teoricamente e empresarialmente esperado, sendo que a influência, também, positiva na variação do ST, denota a preocupação das empresas em manter a liquidez e evitar o efeito tesoura, ou seja, o maior crescimento marginal da NCG frente ao CCL com implicação em ST negativo.

Em adição, a evidência que a NCG passada exerce impacto na NCG presente é um fato não discutido com profundidade nos manuais de finanças, salvo os apontamentos iniciais de Assaf e Silva (2010) quanto aos cálculos de liquidez das contas, por meio da identificação dos investimentos fixos das contas cíclicas em função dos diferentes prazos médios. No entanto, a análise não é direcionada para os efeitos futuros da formação de estoque e contas a receber.

Em função destas evidências, este estudo pode contribuir com a prática empresarial em sugerir, de fato, considerar na análise de investimentos em ativos fixos os reflexos na expansão ou retração (dependendo do investimento) do capital de giro, fato que por vezes não é agregado nos projetos financeiros. Assim como, as decisões que envolvem a expansão do capital de giro (aumento de prazo para pagamento ou ampliação da disponibilidade de estoque) não devem ser consideradas somente para o curto prazo, mas para exercícios futuros, pois o ciclo operacional possui uma inercia que não é superada no exercício seguinte.

Ainda, o efeito positivo dos investimentos em imobilizado no ST e NCG reforçam que as fontes de financiamento de LP devem ser suficientes para garantir o Imobilizado e a folga financeira para que a empresa não incorra em efeito tesoura, onde o negócio é inviabilizado pela ausência de liquidez, mesmo que o investimento apresente retorno positivo. 
A construção destes resultados apresentou algumas limitações que devem ser retomadas para garantir confiabilidade nas interpretações. Os resultados são restritos às empresas utilizadas, selecionadas pela conveniência do acesso aos dados. Tomou-se o cuidado em trabalhar com o maior número possível de empresas listadas na BM\&FBOVESPA não financeiras ( 255 no total para o período de 2010 a 2014), porém esse quantitativo não representa a totalidade de empresas do país, por isso, a extrapolação deve ser cuidadosa quanto ao contexto econômico, setorial e temporal para cada unidade a ser analisada.

Outra restrição deve-se as técnicas quantitativas empregadas. O modelo empírico proposto pressupõe linearidade nas variáveis e os coeficientes são fixos, o que pode não ser o caso para diferentes níveis, além disso, a presença de autocorrelação e ausência de normalidade nos resíduos implica em não utilizar os coeficientes para fins de estimação. Lembra-se, contudo, que essas restrições, semelhantes em outros estudos, e naturais em processos de pesquisa não inviabilizaram os resultados e a análise proposta, apenas, oferecem contornos que devem ser observados para garantir uma análise acurada.

Sugere-se como pesquisas futuras neste tema a análise dos efeitos da inércia dos investimentos em ST e NCG no tempo, por meio do uso de modelos de séries temporais que não foi possível neste estudo. Adicionalmente, é possível explorar esses resultados para setores diferentes, pois como as variáveis de ST e NCG são determinadas pelos ciclos das empresas que são distintos entre setores, a inercia identificada deve ser diferente, resultando assim, em diagnosticar a extensão temporal destes efeitos.

\section{REFERÊNCIAS}

Almeida, J. R., \& Eid Jr., W. (2014) Access to finance, working capital management and company value: Evidences from Brazilian companies listed on BM\&FBOVESPA. Journal of Business Research, 67(5), 924-934.

Assaf Neto, A. (2005) Finanças Corporativas e Valor. (2a ed.). São Paulo: Atlas.

Assaf Neto, A ., \& Silva, C. A. T. (2010) Administração do Capital de Giro. (3a. ed.). São Paulo: Atlas.

Baños-Caballero, S., García-Teruel, P. J., \& Martínez-Solano, P. (2014) Working capital management, corporate performance, and financial constraints. Journal of Business Research, 67(34), 332-328.

Berk, J., Demarzo, P., \& Harford, J. (2010) Fundamentos de Finanças Empresariais. Porto Alegre: Bookman.

Braga, R. (1991) Análise avançada do capital de giro. Caderno de Estudos, 3, 1-20.

Brealey, R. A., Myers, S. C., \& Marcus, A. J. (2002) Fundamentos da Administração Financeira. (3a. ed.). Rio de Janeiro: McGraw-Hill Irwin.

Bussab, W. D., \& Morettin, P. A. (2003) Estatística Básica. (5a. ed.). São Paulo: Saraiva.

Camargos, M. A., Camargos, M. C. S., \& Leão, L. C. G. (2014) Empirically testing the "Fleuriet's model": Evidences of Brazilian Market. Business and Management Review, 92(Special Edition), 165-177.

Carvalho, C. J., \& Schiozer, R. F. (2012) Gestão de Capital de Giro: um Estudo Comparativo entre 
Práticas de Empresas Brasileiras e Britânicas. Revista de Administração Contemporânea, 16(4), 518-543.

Fleuriet, M. J. (2005) Fleuriet's Rebuttal to 'Questioning Fleuriet's Model of Working Capital Management on Empirical Grounds'. [Working Paper n. 741624]. Social Science Research Network. Rochester, NY.

Fonseca, J. L., \& Ceretta, P. S. A (2012) Gestão da Liquidez e o seu reflexo no retorno sobre o capital próprio e no lucro por ação das empresas pertencentes à BMF\&BOVESPA. Revista Alcance, 19(2), 202-221.

Frezatti, F., Bido, D. S., Cruz, A. P. C., Barroso, M. F. G., \& Machado, M. J. C. (2012) Decisões de Investimento em Ativos de Longo Prazo nas Empresas Brasileiras: Qual a Aderência ao Modelo Teórico? Revista de Administração Contemporânea. 16(1), 1-22.

Gimenes, R. M., \& Gimenes, F. M. (2008) Aplicabilidade da Análise Dinâmica do Capital de Giro como Instrumento de Avaliação da Gestão Financeira em Cooperativas Agropecuárias. Revista Economia Contemporânea, 12(1), 129-150.

Guimarães, A. L. S., \& Nossa, V. (2010) Working capital, profitability, liquidity and solvency of healthcare insurance companies. BBR - Brazilian Business Review, 7(2), 37 - 59.

Gujarati, D. (2006) Econometria Básica. São Paulo: Campus.

Jones, G. D., \& Jacinto, A. C. (2013) Análise da Gestão dos Investimentos em Capital de Giro por meio do Modelo Fleuriet em uma Empresa do Agronegócio: Um Estudo de Caso. Revista em Agronegócios e Meio Ambiente, 6(1), 9-30.

Knauer, T., \& Wöhrmann, A. (2013) Working capital management and firm profitability. Journal of Management Control, 24(1), 77-87.

Lind, L., Pirttilä, M., Viskari, S., Schupp, F., \& Kärri, T. (2012) Working capital management in the automotive industry: Financial value chain analysis. Journal of Purchasing \& Supply Management, 18(2), 92-100.

Loncan, T. R., \& Caldeira, J. F. (2014) Estrutura de capital, liquidez de caixa e valor da empresa: estudo de empresas brasileiras cotadas em bolsa. Revista Contabilidade \& Finanças, 25(64), 46-59.

Marques, J. A., \& Braga, R. (1995) Análise Dinâmica do Capital de Giro. O Modelo Fleuriet. Revista de Administração de Empresas, 35(3), 49-63.

Matias, A. B. (2007) Finanças Corporativas de Curto Prazo. São Paulo: Atlas.

Medeiros, O. R., \& Rodrigues, F. F. (2004) Questionando Empiricamente a Validade do Modelo Fleuriet. Revista de Administração e Contabilidade da Unisinos, 1(2), 25-32.

Modigliani, F., \& Miller, M. H. (1958) The cost of capital, corporation finance and the theory of investment. American Economic Review, 48(3), 261-297.

Mongrut, S., Fuenzalida, D., Cubillas, C., \& Cubillas, J. (2014) Determinants of Working Capital Management in Latin American Companies. Innovar, 24(51), 5-18.

Nascimento, C. D., Espejo, M. M., Voese, S. B., \& Pfitscher, E. D., \& Teles, J. (2013) Crise Financeira de 2008 em meio à Gestão do Capital de Giro de Empresas do Setor Industrial Brasileiro. Revista de Gestão Industrial, 9(2), 465-483. 
Oliveira, A. M., Ramalho, R., \& Moura, A. A. (2013) Gestão de Capital de Giro Líquido e de Fluxo de Caixa em Risco de Empresas de Bens Industriais Listadas na BM\&FBOVESPA. Revista de Contabilidade UFBA, 7(2), 38-51.

Paixão, R. B., Bruni, A. L., Murray, A. D., \& Garcia, M. (2008) Análise dinâmica do setor comercial nacional: uma aplicação do modelo Fleuriet. Revista Gestão e Planejamento, 9(2), 199-216.

Palombini, N. V.\& Nakamura, W. T. (2012) Key factors in working capital management in the Brazilian market. Revista de Administração de Empresas, 52(1), 55-69.

Perobelli, F. F. C., Pereira, J. F., \& David, M. V. (2006, setembro) Relação liquidez-retorno: existiria também uma "estrutura de liquidez" ideal para cada perfil de empresa? Anais do Encontro Anual da Associação Nacional de Programas de Pós-Graduação em Administração, Salvador, BA, Brasil, 30 .

Rodrigues, S. V., Moura, H. J., \& Santos, D. F. L. (2011) O relacionamento entre o ciclo financeiro e a estrutura de capital de giro das empresas sustentáveis do ISE da BM\&FBOVESPA. Ciências Sociais Aplicadas em Revista, 11(21), 153-169.

Ross, S. A., Westerfield, R. W., \& Jordan, B. D. (2000) Princípios de Administração Financeira. (2a. ed.). São Paulo: Atlas.

Silva, S. S., Botelho, D. O., \& Ferreira, P. A. (2009) Influência da liquidez sobre o lucro empresarial. Revista Ingepro: Inovação, Gestão e Produção, 3, 64-72.

Starke Jr., P. C.,Freitag, V. D., \& Cherobim, A. P. A (2008) Erraticidade das Contas Circulantes Financeiras: uma resposta a questões sobre o Modelo Fleuriet. Revista de Informação Contábil, 2(3), 43-60.

Teruel, P. J. G., \& Solano, P. M. (2006) Effects of working capital management on SME profitability. [Working Paper id 894865]. Social Science Research Network. Rochester, NY.

Weinraub, H. J., \& Visscher, S. (1998) Industry Practice Relating to Aggressive Conservative Working Capital Policies. Journal of Financial and Strategic Decisions, 11(2), 11-18.

Zouain, D. M., Ferreira, C. C., Macedo, M. A. S., Sant'Anna, P. S., Longo, O. C., \& Barone, F. M. (2011) Gestão de capital de giro: contribuição para as micro e pequenas empresas no Brasil. Revista de Administração Pública, 45(3), 863-884. 